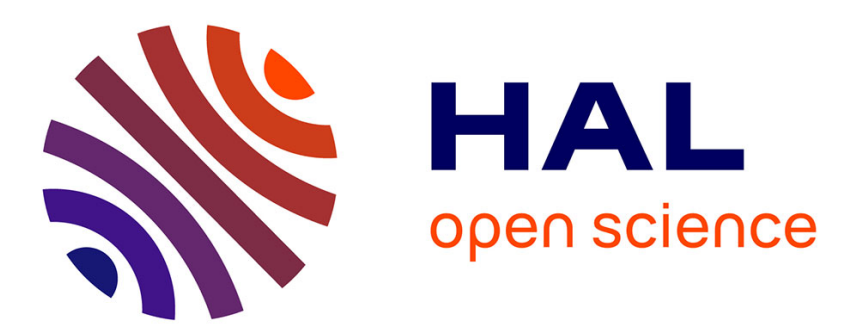

\title{
Synthesis and electroactivated addressing of ferrocenyl and azido-modified stem-loop oligonucleotides on an integrated electrochemical device
}

\author{
Lucian-Gabriel Zamfir, Philippe Fortgang, Carole Farre, Micaël Ripert, \\ Gabriel de Crozals, Nicole Jaffrezic-Renault, Camelia Bala, Pierre \\ Temple-Boyer, Carole Chaix
}

\section{To cite this version:}

Lucian-Gabriel Zamfir, Philippe Fortgang, Carole Farre, Micaël Ripert, Gabriel de Crozals, et al. Synthesis and electroactivated addressing of ferrocenyl and azido-modified stem-loop oligonucleotides on an integrated electrochemical device. Electrochimica Acta, 2015, 164, pp.62-70. 10.1016/j.electacta.2015.02.167 . hal-01227342

\section{HAL Id: hal-01227342 \\ https://hal.science/hal-01227342}

Submitted on 10 Nov 2015

HAL is a multi-disciplinary open access archive for the deposit and dissemination of scientific research documents, whether they are published or not. The documents may come from teaching and research institutions in France or abroad, or from public or private research centers.
L'archive ouverte pluridisciplinaire HAL, est destinée au dépôt et à la diffusion de documents scientifiques de niveau recherche, publiés ou non, émanant des établissements d'enseignement et de recherche français ou étrangers, des laboratoires publics ou privés. 


\title{
Synthesis and electroactivated addressing of ferrocenyland azido-modified stem- loop oligonucleotides on an integrated electrochemical device
}

\author{
Lucian Zamfir ${ }^{1,2}$, Philippe Fortgang ${ }^{1}$, Carole Farre ${ }^{1}$,Micaël Ripert ${ }^{1}$, Gabriel De \\ Crozals ${ }^{1}$, Nicole Jaffrezic-Renault ${ }^{1}$, Camelia Bala ${ }^{2,3}$, Pierre Temple-Boyer ${ }^{4,5}$, \\ Carole Chaix ${ }^{1 *}$ \\ ${ }^{1}$ Institut des Sciences Analytiques, CNRS/Université Lyon 1, 5 rue de la Doua, 69100 Villeurbanne, \\ France \\ carole.chaix@isa-lyon.fr \\ ${ }^{2}$ LaborQ, University of Bucharest, 4-12 Regina Elisabeta Blvd., 030018 Bucharest, Romania \\ ${ }^{3}$ Department of Analytical Chemistry, University of Bucharest, 4-12 Regina Elisabeta Blvd., 030018 \\ Bucharest, Romania \\ ${ }^{4}$ CNRS, LAAS, 7 avenue du colonel Roche, F-31400 Toulouse, France \\ ${ }^{5}$ Université de Toulouse, UPS, LAAS, F-31400 Toulouse, France
}

\begin{abstract}
We report a strategy to address stem-loop oligonucleotides on a gold surface in order to develop a robust and ultra-sensitive integrated electrochemical DNA sensor. The probe immobilization relies on the potential-assisted copper-catalyzed alkyne-azide cycloaddition. Firstly, a tetrathiol-hexynyl derivative was used to introduce alkyne functions on the electrode surface. This anchor proved its robustness in conditions used for the "click" reaction and in wet storage. Then, different ferrocenyl and azido-modified stem-loop oligonucleotides were synthesized by solid-phase synthesis and their immobilization was studied. Hybridization assays with the DNA target were achieved in complex medium by cyclic voltammetry. The detection sensitivity reached by our functionalized electrodes was significantly increased as a detection limit of $10 \mathrm{fM}$ was determined. We also demonstrated that the graftingof the stem-loop oligonucleotides viathe electroactivated "click" reaction was specific of the gold surface, on amicrofabricatedelectrochemical device for Lab-on-Chip application that fully integrates the Au working microelectrodes, Pt counter and Ag reference electrodes.
\end{abstract}

\section{Keywords}

\section{Introduction}

Nucleic acids are precious biological tools that are frequently used to elaborateanalytical devices dedicated to medical diagnostics. Their sequence-specific binding properties are exploited tocontrol either theirarchitecture, for instance by the way of a stem-loop structure, or thepatterning on a support by self-assembly such as for DNA origami[1].The conformational changeof a DNA probe induced by the binding process is frequently exploited to developelectrochemical DNA sensors. Fan et al.[2] and Immoos et al.[3] pioneered the use of ferrocene( $\mathrm{Fc})$ modified stem-loop DNA as capture probes for sensors. Probe binding with its complementary DNA target induces a conformationalchange which is followed by electrochemical methods. In our laboratory, we developed strategies for modifying oligonucleotide sequences with many ferrocene derivatives, directly during DNA automated solid-phase synthesis[4-8]. A stem-loop DNA labeled with four Fc molecules was synthesized and used as a probe in a gold electrode microsensor to accomplish DNA target detection[9].A detection limit of $3.5 \mathrm{pM}$ was reached by this DNA sensor.

The electrochemical methods can be easily adapted to a multiplexed format. The addressing of probes on a multi-detection system is a crucial step that directly impacts biochip performance.Devaraj et al. first described the addressing of a ferrocene derivative on independent gold microelectrodes by electrochemical activation of the alkyne/azide cycloaddition (Sharpless "click" reaction)[10].This 
group introduced a method by which the active $\mathrm{Cu}(\mathrm{I})$ catalyzing the 1,2,3-triazole formation between a terminal alkyne and an organic azidewas selectively and locally generated under a negative potential on the electrode. They demonstrated that this technique can provide a spatial resolution of the grafting reaction[11].Canete and Lai reported the elaboration of a multi-detection system by addressing stemloop oligonucleotides $(\mathrm{ON})$ onto an electrode array through the $\mathrm{Cu}(\mathrm{I})$ electrocatalyzed "click" reaction [12]. A three-probe DNA sensor was developed that could simultaneously detected three different DNA targets at $1 \mu \mathrm{M}$ concentration.Furst et al. recently reported the same grafting method for DNA patterning ona two-electrode platform[13].

In our laboratory, we described a new approach to produce robust sensor arraysviathe $\mathrm{Cu}(\mathrm{I})$ electrocatalyzedazide/alkyne cycloaddition[14].It consists ofusinga tetrathiol anchor grafted on gold electrodes to enhance the stability of the tethered entities in buffer and allow efficient surface coverage. A bis(dithiolphosphate)hexynyl derivative was synthesized. The compound provideda tetrathiolbound on gold electrode. The alkyne function of the linker allowed achievingthe "click" reaction. The gain of stability provided by thismultidental anchor was confirmed, allowing several regenerations of the sensor.

In this paper, we focus on addressing ferrocene-modified stem-loop oligonucleotides on gold electrodes viathe $\mathrm{Cu}(\mathrm{I})$ electrocatalyzedazide/alkyne "click" reaction. Electrochemical characterization of the functionalized electrodes is presented. Hybridization study permitted to determine a detection limit of the complementary DNA target at $10 \mathrm{fM}$ that is much better than the sensitivity reached by previously described stem-loop DNA sensors developed with different grafting strategies[9, 15].

We also confirmed the robustness of the sensitive layer on the sensor that allowed several regenerations of the system. Finally, we investigated the electrocatalyzed "click" reaction on an integrated electrochemical device, constructed with a gold working microelectrode of $19.6 \times 10^{-4} \mathrm{~mm}^{2}$, a platinum counter electrode of $1 \mathrm{~mm}^{2}$ and a Ag/AgClreference electrode of $2 \times 10^{-2} \mathrm{~mm}^{2}$. A fluorescent azide-modified oligonucleotide was electroaddressed following our protocol. Fluorescence recorded by microscopy confirmed the selective functionalization of the gold surface.

\section{Experimental}

\subsection{Chemicals}

Potassium phosphate monobasic ( $\geq 98 \%$ ), sodium perchlorate and tris[(1-benzyl-1H-1,2,3triazol-4-yl)methyl]amine (TBTA), tris(2-carboxyethyl)phosphine hydrochloride (TCEP/HCl), all other solvents and chemicals were purchased from Sigma-Aldrich. Sodium phosphate dibasic dihydrate $(\geq 99 \%)$, celite and silica gel were obtained from Fluka. Sodium hydroxide was obtained from Laurylab.Phosphoramidites, dT-CPG column, reagents and solvents used for DNA synthesis were purchased from Glen Research (Sterling, Virginia). The salmon sperm DNA (10 mg/mL) was purchased from Invitrogen. The non-complementary target ${ }^{5}$ 'TTT TTA TTG AGA TTC CCG AGA TTG ATT TTT $\left.^{3}{ }^{3}\right)$ and the complementary influenza target $\left({ }^{5}\right.$ 'TTT TTTTTT TAG TTT TTG GAC GTC TTC TCC TTT TTTTTT $\mathrm{T}^{3}$ ) were obtained from Eurogentec.The fluorescent (Cyanine5) oligonucleotide $\left(5^{\prime} \mathrm{C}_{6} \mathrm{H}_{12} \mathrm{~N}_{3}\right.$-TTT TTT TTT T Cy5 G 3') was synthesized in the laboratory using standard DNA solid-phase synthesis methods. ESI Mass Spectrometry was conducted on a Bruker micrOTOF-Q II and MALDI-TOF MS on an Applied Biosystems Voyager DE-PRO (Foster city, USA), using 2,4,6-trihydroxyacetophenone monohydrate (THAP) as the matrix. ${ }^{1} \mathrm{H}$ NMR spectra were recorded on a DRX 300 Bruker spectrometer.

\subsection{Synthesis of the (DTPA) $)_{2}$ hexynyl linker}

The (DTPA) 2 hexynyl linker was synthesized by a solid-phase approach according to a protocol previously described [14]. The purity was controlled by high performance liquid chromatography and a global yield of $80 \%$ was estimated by UV spectroscopy.

\subsection{Synthesis of the oligonucleotides (DTPA) $)_{2} \operatorname{In} 4 \mathrm{Fc}, \mathrm{N}_{3} \operatorname{In}{ }^{\prime} 1 \mathrm{Fc}$ and $\mathrm{Tb}\left(\mathrm{N}_{3}\right)_{3} \operatorname{In}{ }^{\prime} 4 \mathrm{Fc}$}


The oligonucleotides were synthesized with an automated instrument via the phosphoramidite chemistry, according to a standard protocol. A dT-CPG column was used to start each synthesis.All the resulting oligonucleotidic sequences ended with a thymidine at the 3'extremity. The synthesis was achieved via the standard $1 \mu \mathrm{M}$ phosphoramidite cycle on the synthesizer. The bifunctionalferrocenephosphoramidite (1-[3-O-dimethoxytritylpropyl]-1-[3-O-(2-cyanoethyl-N,Ndiisopropylphosphoramidityl)propyl]ferrocene) was used in the DNA synthesizer to incorporate $\mathrm{Fc}$ directly into the oligonucleotide sequence during solid-phase synthesis. A coupling time of 30 seconds was applied for the incorporation of the ferrocenesynthon $(0.1 \mathrm{M}$ in Acetonitrile $(\mathrm{AcCN}))$. For the (DTPA) $)_{2}$ In $4 \mathrm{Fc}$, two successive incorporations of the dithiolphosphoramiditesynthon (DTPA) were achieved at the end of synthesis, following the protocol recommended by Glen Research. For the $\mathrm{N}_{3} \mathrm{In}$ '1Fc, the 5'-bromohexyl phosphoramidite was incorporated at the 5' extremity with a coupling yield > 98\%. For the $\mathrm{Tb}\left(\mathrm{N}_{3}\right)_{3} \mathrm{In}{ }^{\prime} 4 \mathrm{Fc}$, the treblersynthon (Tris-2,2,2-[3-(4,4'dimethoxytrityloxy)propyloxymethyl]ethyl-[(2-cyanoethyl)-(N,N-diisopropyl)]phosphoramidite) was incorporated at the 5, extremity with a coupling yield of $85 \%$ before coupling the bromohexylphosphoramidite. The $\mathrm{N}_{3} \mathrm{In}$ ' $1 \mathrm{Fc}$ and $\mathrm{Tb}\left(\mathrm{N}_{3}\right)_{3} \mathrm{In}$ ' $4 \mathrm{Fc}$ functionalized $\mathrm{CPG}$ were then suspended in $2 \mathrm{~mL}$ of a solution of sodium azide $(100 \mathrm{mM})$, sodium iodide $(100 \mathrm{mM})$ in anhydrous DMF in order to substitute the bromo functions to azides. The reaction was performed for 2 hours at $65^{\circ} \mathrm{C}$. After the cleavage and deprotection step in $1 \mathrm{~mL}$ of concentrated $\mathrm{NH}_{4} \mathrm{OH}\left(30 \% / \mathrm{H}_{2} \mathrm{O}\right), 16$ hours at $60^{\circ} \mathrm{C}$, the crude materials were concentrated to dryness in a speed-vacuum instrument. The oligonucleotides were purified by HPLC using a DeltaPak C18 $15 \mu \mathrm{m} 300 \AA$ (300 x $7.8 \mathrm{~mm})$ column with an acetonitrile gradient from 0 to $50 \%$ in $0.05 \mathrm{M}$ triethylammonium acetate buffer (TEAAc), pH 7. Oligonucleotide purity was controlled by HPLC using an X-terra MS C18 $2.5 \mu \mathrm{m}(50$ x 4.6) column from Waters (Versailles, France). Analyses were carried out with an acetonitrile gradient from 5 to $50 \%$ in $0.05 \mathrm{M}$ TEAAc, $\mathrm{pH} 7$, in $65 \mathrm{~min}$ at $60^{\circ} \mathrm{C}$. Then, the oligonucleotide was characterized by MALDI-TOF MS analysis $(\mathrm{M}-\mathrm{H})^{-}\left(\mathrm{g} \mathrm{mol}^{-1}\right): 10185.2$ for(DTPA) $)_{2} \mathrm{In} 4 \mathrm{Fc}$ (Calculated : 10187.49); 10771.0 for $\mathrm{N}_{3} \mathrm{In}$ '1 Fc (Calculated : 10773.8); 12641.9 for $\mathrm{Tb}\left(\mathrm{N}_{3}\right)_{3} \mathrm{In}$ '4 Fc (Calculated : 12646.4).

\subsection{Electrochemical materials}

Aqueous buffers were made with deionized water purified through a Milli-Q system (Millipore, Bedford, MA). All analyses were conducted in PBE (phosphate buffer electrolyte: sodium phosphate dibasic and potassium phosphate monobasic $\left.(20 \mathrm{mM}), \mathrm{NaClO}_{4}(250 \mathrm{mM}), \mathrm{pH} 6.4\right)$. The solutions were deoxygenated under argon before use. Electrochemical measurements were carried out in a conventional one compartment-three electrode cell with an internal volume of $5 \mathrm{~mL}$ (VerreEquipements, Collonges au Mont d'Or, France), hermetically closed on one side with a planar gold electrode (active surface of $7 \mathrm{~mm}^{2}$ ) used as the working electrode and, on the other side, a planar platinum electrode (active surface of $38.5 \mathrm{~mm}^{2}$ ) used as the counter electrode. A $\mathrm{KCl}$ saturated calomel electrode (SCE) from Radiometer Analytical (Villeurbanne, France) was used as a reference for aqueous solution and an $\mathrm{Ag} / \mathrm{Ag}+$ reference electrode from ALS Japan (Ag wire in acetonitrile containing $0.01 \mathrm{M} \mathrm{AgNO}_{3}$ and $0.1 \mathrm{M}$ tetrabutylammonium perchlorate) for non-aqueous solvents. This system was connected to a Bio-Logic potentiostat VMP2 (Bio-Logic Science Instruments, Pont de Claix, France). Results were recorded using EC-Lab software from Bio-Logic Science Instruments. In this work, we addressed and recorded the responses of the gold electrode by cyclic voltammetry $(\mathrm{CV})$.

$(\mathrm{Au}-\mathrm{Pt}-\mathrm{Ag})$ electrochemical microcells (ElecCell) devices were fabricated using silicon technology [16]. This electrochemical microdeviceintegrates on an oxidized (silicon oxide thickness: $1 \mu \mathrm{m}$ ) silicon substrate a gold working microelectrode, a platinum counter microelectrode and a silver microelectrode to be used as an integrated reference one. The different metallic layers were deposited by evaporation techniques, and patterned using a bilayer lift-off process. Three depositions were performed in a row: firstly, a $120 \mathrm{~nm}$ platinum layer was deposited on a $20 \mathrm{~nm}$ titanium underlayer in order to ensure platinum adhesion on silicon oxide $\mathrm{SiO}_{2}$, followed by a $400 \mathrm{~nm}$ gold and a $400 \mathrm{~nm}$ silver layer. Finally, a biocompatible $\mathrm{Si}_{3} \mathrm{~N}_{4}$ passivation layer (thickness: $100 \mathrm{~nm}$ ) was deposited at the wafer level and patterned using photolithography techniques [17].According to this final wafer-level passivation process, the different metallic layers were insulated electrically and their active surfaces were defined precisely.The gold working microelectrode was defined as a disk of $19.610^{-4} \mathrm{~mm}^{2}$ 
(diameter: $50 \mu \mathrm{m})$. In contrast, a very large silver/silver chloride reference microelectrode $\left(0.02 \mathrm{~mm}^{2}\right)$ and platinum counter microelectrode $\left(1 \mathrm{~mm}^{2}\right)$ were co-integrated. The whole silicon chip was then wire bonded and packaged on a specifically coated printed circuit to be compatible with liquid phase measurement (see Supplementary information).The gold squares and ElecCell devices were gratefully furnished by the LAAS-CNRS (Toulouse - France).

\subsection{Activation of the gold surface}

The gold electrode was sonicated in acetone for 15 minutes. The surface was cleaned with ethanol and ultrapure water and dried with argon. The electrode was positioned on the electrochemical cell and $4 \mathrm{~mL}$ of $\mathrm{NaOH}$ solution $0.5 \mathrm{M}$ were added. The gold surfaces were activated by cycling 10 times between -0.4 and $-1.4 \mathrm{~V} v s$.SCE, with a scan rate of $0.05 \mathrm{~V} \mathrm{~s}^{-1}$. The gold electrode was washed with ultrapure water and dried with an argon flow.

\subsection{Electrode functionalization with the tetrathiol-modified oligonucleotide (DTPA) ${ }_{2} \mathrm{In} 4 \mathrm{Fc}$}

Prior to thiolgrafting onto the gold surface, $1 \mu \mathrm{L}$ of tris(2-carboxyethyl) phosphine hydrochloride (TCEP/ $\mathrm{HCl}, 160 \mathrm{mM}$ in water) was added to $1 \mathrm{nmol}$ of (DTPA) ${ }_{2} \mathrm{In} 4 \mathrm{Fc}$ in $5 \mu \mathrm{L}$ of water and the reduction was carried out for 2 hours. In parallel, gold surfaces were activated using the method previously described. Then, (DTPA) $)_{2} \mathrm{In} 4 \mathrm{Fc}$ functionalized electrode was prepared by soaking the freshly activated gold surface at room temperature under argon in $96 \mu \mathrm{L}$ of phosphate buffer solution $(\mathrm{PB}, 100 \mathrm{mM}), \mathrm{pH} 8$ containing reduced $(\mathrm{DTPA})_{2} \mathrm{In} 4 \mathrm{Fc}(10 \mu \mathrm{M})$ and TCEP/HCl $(1.6 \mathrm{mM})$ during 3 days, according to the protocol described by Ricci et al. [18]. Then, after rinsing the electrode with water, the system was passivated by soaking for $1 \mathrm{~h}$ in $60 \mu \mathrm{L}$ of a solution of mercaptopropanol $(1 \mathrm{mM})$ in water and finally rinsed with water.

\subsection{Electrode functionalization with the azideferrocene oligonucleotides $\mathrm{N}_{3} \operatorname{In}{ }^{\prime} 1 \mathrm{Fc}$ and $\mathrm{Tb}\left(\mathrm{N}_{3}\right)_{3} \operatorname{In}{ }^{\prime} 4 \mathrm{Fc}$}

Prior to thiolgrafting onto the gold surface, $1 \mu \mathrm{L}$ of TCEP/HCl (160 $\mathrm{mM}$ in water) was added to $5 \mu \mathrm{L}$ of (DTPA) ${ }_{2}$ hexynyl $1(0.8 \mathrm{mM}$ in water) to reduce the thiol functions[19]. The gold surfaces were activated as described in the precedent part. The (DTPA) 2 hexynyl functionalized electrodes were prepared by soaking the freshly activated gold surface at room temperature under argon in $96 \mu \mathrm{L}$ of phosphate buffer solution $(100 \mathrm{mM})$, pH 8 containing reduced (DTPA) $)_{2}$ hexynyl $1(40 \mu \mathrm{M})$ and $\mathrm{TCEP} / \mathrm{HCl}(1.6 \mathrm{mM})$ during 3 days. Then, after rinsing the electrode with water, the system was passivated by soaking for $1 \mathrm{~h}$ in $60 \mu \mathrm{L}$ of a solution of mercaptopropanol $(1 \mathrm{mM})$ in water and finally rinsed with water. The electrode was used immediately after preparation in order to "click" the azideferrocene oligonucleotides. The "click" reaction procedure used was similar to that described by Devaraj et al. [10]and Canete and Lai[12]. The modified electrode was thoroughly rinsed with water, and incubated in $4 \mathrm{~mL}$ of $10 \mu \mathrm{M}$ TBTA, $10 \mu \mathrm{M} \mathrm{CuSO}_{4}$ and $1 \mu \mathrm{M}$ of the azideferrocene oligonucleotide in a mixed solution of DMSO/water (50/50). The "click" reaction proceeded in chronoamperometryfor $2 \mathrm{~h}$ with an applied potential of $-300 \mathrm{mV}$ vs. $\mathrm{Ag} / \mathrm{Ag}^{+}$. The electrode was rinsed thoroughly with water and then with PBE to remove physically adsorbed substances.

\subsection{Electrochemical measurements and characterization}

Before analysis, the grafted electrode was washed with water and finally with PBE. Electrochemical measurements were performed in $5 \mathrm{~mL}$ of PBE. Cyclic voltammograms were recorded within a potential range from $0.1 \mathrm{~V}$ to $0.9 \mathrm{~V}$ vs. SCE. For each measurement, 3 successive cycles were carried out to ensure signal stabilization and the third cycle was kept as the result. To determine the electron transfer constant $k_{\mathrm{et}}$, the same cyclic voltammetry $(\mathrm{CV})$ measurements were conducted at increasing scan rates, from $0.05 \mathrm{~V} \mathrm{~s}^{-1}$ to $5 \mathrm{~V} \mathrm{~s}^{-1}$.

\subsection{Hybridization assays in complex medium}


The functionalized electrodes were immerged in water (milliQ grade) and incubated at $70^{\circ} \mathrm{C}$ for one minute. After a rapid wash in water, the electrochemical cell was filled with buffer and the current intensity of the oxidation peak was measured every 15 minutes for 2 hours.Then, PBE buffer was changed to complex medium made of PBE implemented with 20 nMof non-complementary target, 50 $\mu \mathrm{g} \mathrm{mL} \mathrm{L}^{-1}$ of salmon sperm DNA and deoxygenated under argon before use. The signal stabilization was followed by $\mathrm{CV}$ for 3 hours. Hybridization assays were performed by recording $\mathrm{CV}$ (from $0 \mathrm{~V}$ to 0.9 $\mathrm{V} v s$. SCE, scan rate of $0.1 \mathrm{~V} \mathrm{~s}^{-1}$ ) each 15 minutes after adding in the solution the non-complementary target (NCT) or the complementary target (CT) at different concentrations.

\section{Results and discussion}

3.1. Grafting strategy of the (DTPA) $)_{2}$ hexynyl or (DTPA $)_{2} \operatorname{In} 4 \mathrm{Fc}$ derivative

Fig. 1.Gold electrode functionalization with the tetrathiol derivatives ((DTPA) $)_{2}$ hexynyl or $\left.(\mathrm{DTPA})_{2} \mathrm{In} 4 \mathrm{Fc}\right)$

Gold electrode functionalization was achieved withtetrathiol derivatives. Thetetrathiololigonucleotide (DTPA) ${ }_{2}$ In4Fcwas used for direct grafting. Thiols were first reduced with the tris(2carboxyethyl) phosphine hydrochloride (TCEP) prior to react with freshly activated gold surfaces, as described in the experimental part. The probe addressing via the "click" reaction was achieved in two steps. The first step was the gold surface functionalization by alkyne functions using the (DTPA) $)_{2}$ hexynyllinker. A passivation step was performed with mercaptopropanol to forma mixed compact layer of (DTPA) $)_{2}$ derivative and mercaptopropanol.The latter was used as a diluent of the hexynyl functions and for passivation of the electrode. The second step was the probe immobilizationvia the electroactivated "click" reaction.

\subsection{Design and synthesis of the ferroceneazideoligonucleotides}

The stem-loop sequences described in this article (Table 1) were designed by bioMerieux for Influenza B virus RT-PCR product analysis[9]. Previous thermodynamic studies demonstrated that the 
folded structure was not destabilized by incorporating numerous $\mathrm{Fc}$ molecules inside or at the extremities of the hairpin[7].Ferrocenes bound to oligonucleotide probes act as electrochemical markers, affording a sharp electrochemical response which is highly sensitive to ionic and steric surrounding media. In the literature, Fc modified stem-loop structures have already been described as efficient probes for electrochemical DNA detection after anchoring on electrode surfaces [20-22].In comparison to the papers already published in this field, the main advantage of our work lies in the easy incorporation of numerous ferrocenes in the probes to enhance the electrochemical response of the DNA sensor.

Table 1. Theoretical $T_{m}$ values of In and In' hairpins calculated from the free software

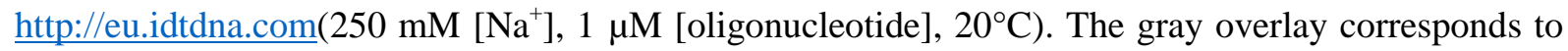
the binding part with the complementary target. $*$ The $\mathrm{T}_{\mathrm{m}}$ duplex was calculated with the complementary strand of the loop.

\begin{tabular}{c|ccc}
\hline $\begin{array}{c}\text { ON } \\
\text { probe }\end{array}$ & sequence & $\begin{array}{c}T_{m} \text { hairpin self- } \\
\text { folding }\left({ }^{\circ} \mathrm{C}\right)\end{array}$ & $\begin{array}{c}T_{m} \text { duplex }^{*} \\
\left({ }^{\circ} \mathrm{C}\right)\end{array}$ \\
\hline In & $\begin{array}{c}\text { s. }^{\prime} \text { CGA TCG GAA GAC GTC CAA AAC GAT } \\
\text { CG }^{3}\end{array}$ & 60.4 & 54.1 \\
In' & $\begin{array}{c}{ }^{5} \text { CTG CTA GGG AGA AGA CGT CCA } \\
\text { AAA ACT AGC AG }\end{array}$ & 56.7 & 63.8 \\
\hline
\end{tabular}

The melting temperature $(\mathrm{Tm})$ values were calculated directly from the sequences. This parameter gives relevant information on the thermodynamics of the DNA systems. Considering the sequences, two different equilibria were observed. With a Tm of $60.4^{\circ} \mathrm{C}$, the hairpin structure is favored in the case of In sequence. On the other hand, duplex gives a higher Tm than hairpin for the In' sequence. The two sequences have been chosen to compare the influence of the hairpin structure on the performance of the DNA electrochemical assay. 
Fig. 2.Structures of the probes a) $\mathrm{N}_{3} \mathrm{In}$ ' $1 \mathrm{Fc}$ and b) $\mathrm{Tb}\left(\mathrm{N}_{3}\right)_{3} \mathrm{In}$ '4Fclmages could be on one row

$\mathrm{N}_{3}$ In' $1 \mathrm{Fc}$ and $\mathrm{Tb}\left(\mathrm{N}_{3}\right)_{3} \mathrm{In}$ ' $4 \mathrm{Fc}$ probes are 32 mer hairpin oligonucleotides bearing one or four successive Fc-phosphates at the 3' end, respectively. As described in Fig. 2, $\mathrm{N}_{3} \mathrm{In}$ ' $1 \mathrm{Fc}$ is functionalized at the 5 'end by an azidohexyl arm. $\mathrm{Tb}\left(\mathrm{N}_{3}\right)_{3} \mathrm{In}$ '4 $\mathrm{Fc}$ bears a tridental azido arm. The oligonucleotides were synthesized using standard phosphoramidite chemistry. The ferrocenephosphoramidite used in the study was synthesized according to the protocol described by Chatelain et al. [9].The three azidearms of $\mathrm{Tb}\left(\mathrm{N}_{3}\right)_{3}$ In'4Fcwereincorporated at the 3'endby reaction on a tridental "trebler" linker directly during oligonucleotide synthesis, as described in the experimental part.Oligonucleotides were purified by HPLC and analyzed by mass spectrometry (MALDI-MS) (see Supplementary information).

\subsection{Grafting strategy of the $\mathrm{N}_{3} \operatorname{In}{ }^{\prime} 1 \mathrm{Fc}$ and the $\mathrm{Tb}\left(\mathrm{N}_{3}\right)_{3} \operatorname{In}{ }^{\prime} 4 \mathrm{Fc}$}

The different steps of the gold electrode functionalization via the "click" reaction are described in Fig. 1 and Fig. 3. Firstly, the (DTPA) 2 hexynyl linker was grafted on the surface. Then, the oligonucleotides were tethered by reactingazide oligonucleotides to alkyne functionalized layer, in presence of $\mathrm{CuSO}_{4}$ and TBTA as a stabilizing ligand of $\mathrm{Cu}(\mathrm{I})$ catalysis[12, 23]. Two hours under -300 $\mathrm{mV} v s . \mathrm{Ag} / \mathrm{Ag}^{+}$was the optimized protocol as described in previous papers[12, 14].The coupling yield was estimated around $55 \%$ with the $\mathrm{N}_{3} \operatorname{In}$ ' $1 \mathrm{Fc}$ and $45 \%$ with the $\mathrm{Tb}\left(\mathrm{N}_{3}\right)_{3} \operatorname{In}$ ' $4 \mathrm{Fc}$ by comparison with the surface coverage reached with the (DTPA) $)_{2} \operatorname{In} 4 \mathrm{Fc}$ (see Table 2). It is worth noting that the resulting 
link between the gold surface and the hairpin probe is much longer via the "click" grafting than via the DTPA grafting. This difference will impact the sensitivity of the hybridization assay.
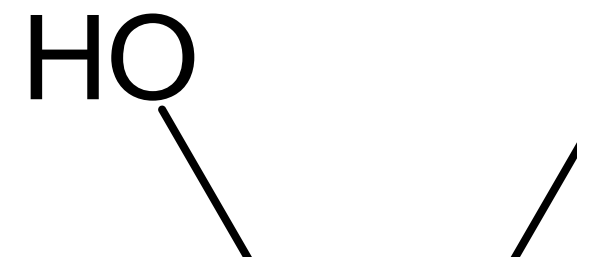

Fig. 3.Grafting strategy of the $\mathrm{N}_{3} \mathrm{In}$ ' $1 \mathrm{Fc}$ probe via the $\mathrm{Cu}(\mathrm{I})$ electrocatalyzed "click" reaction

The hairpin design has been optimized with the In' sequence. It corresponds to a hairpin with seven base pairs in the stem to keep a good stability of the folded structure and eighteen bases in the loop instead of fourteen presented in the In sequence. This longer part of the complementary strand will favor the hairpin opening upon binding with the complementary target.

3.4. Electrochemical properties of the electrodes grafted with the oligonucleotidic probes

The functionalized electrodes were characterized with a standard electrochemical cell using conventional equipment (see Experimental part).The cyclic voltammogramswere recorded from $0 \mathrm{~V}$ to $0.9 \mathrm{~V} v s$. SCE at a scan rate of $0.1 \mathrm{~V} \mathrm{~s}^{-1}$ in order to characterize our systems.

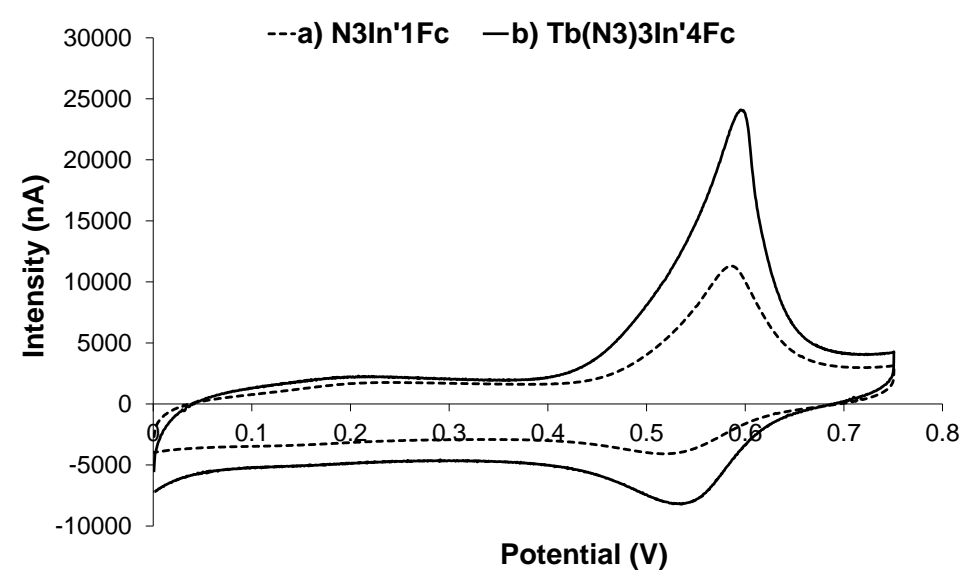

Fig.4.Cyclic voltammograms recorded on a gold electrode functionalized with a) $\mathrm{N}_{3}$ In' $1 \mathrm{Fc}$; b) $\mathrm{Tb}\left(\mathrm{N}_{3}\right)_{3} \mathrm{In}$ ' $4 \mathrm{Fc}$ (scan rate of $0.1 \mathrm{~V} \mathrm{~s}^{-1} v s$. SCE) 
Table 2.Electrochemical properties of the functionalized gold electrodes in a conventional device; reference electrode: $\mathrm{KCl}$ saturated calomel electrode $(S C E)$, scan rate: $0.1 \mathrm{Vs}^{-1}$, electrolytic medium (PBE): phosphate buffer $(20 \mathrm{mM}), \mathrm{NaClO}_{4}(250 \mathrm{mM}), \mathrm{pH} 6.4$.

\begin{tabular}{c|ccccc}
\hline hairpinprobes & $E_{\mathrm{pc}}(\mathrm{V})$ & $E_{\mathrm{pa}}(\mathrm{V})$ & $E_{1 / 2}(\mathrm{~V})$ & $\Delta E(\mathrm{~V})$ & $k_{\mathrm{et}}\left(\mathrm{s}^{-1}\right)$ \\
\hline (DTPA $)_{2}$ In4Fc & 0.53 & 0.58 & 0.55 & 0.05 & 6.3 \\
$\mathrm{~N}_{3} \operatorname{In}{ }^{\prime} 1 \mathrm{Fc}$ & 0.53 & 0.58 & 0.55 & 0.05 & 5.5 \\
$\mathrm{~Tb}\left(\mathrm{~N}_{3}\right)_{3} \operatorname{In}{ }^{\prime} 4 \mathrm{Fc}$ & 0.54 & 0.60 & 0.57 & 0.06 & 5.2 \\
\hline
\end{tabular}

Firstly, the system's oxidation and reduction potentials were determined. CV was performed after stabilization of the systemwhen the hairpin probes were perfectly folded under a stem-loop structure on the gold electrode.Fig. 4 shows $\mathrm{CV}$ of the electrodes functionalized with $\mathrm{N}_{3} \mathrm{In}$ ' $1 \mathrm{Fc}$ and $\mathrm{Tb}\left(\mathrm{N}_{3}\right)_{3} \mathrm{In}$ '4 $\mathrm{Fc}$. The current response of the $\mathrm{Tb}\left(\mathrm{N}_{3}\right)_{3} \mathrm{In}$ ' $4 \mathrm{Fc}$ electrode was clearly enhanced by the fourferrocene tag compared to the $\mathrm{N}_{3} \mathrm{In}$ '1Fc electrode. The $\mathrm{CV}$ profiles were similar to the one obtained from the (DTPA) $)_{2}$ In4Fc functionalized electrode elaborated by a one-step grafting (see Supplementary information). The increased current observed by $\mathrm{CV}$ with the (DTPA) $)_{2} \mathrm{In} 4 \mathrm{Fc}$ and $\mathrm{Tb}\left(\mathrm{N}_{3}\right)_{3} \operatorname{In}{ }^{\prime} 4 \mathrm{Fc}$ electrodes confirms the interest of using a polyferrocene label to improve sensor performance.

An $E_{1 / 2}$ of $0.55 \mathrm{~V} v s$. SCE was measured for (DTPA) 2 In $4 \mathrm{Fc}$ electrode, $E_{1 / 2}$ of $0.55 \mathrm{~V}$ and $0.57 \mathrm{~V}$ were recorded for $\mathrm{N}_{3} \mathrm{In}$ ' $1 \mathrm{~F}$ cand $\mathrm{Tb}\left(\mathrm{N}_{3}\right)_{3} \mathrm{In}$ ' $4 \mathrm{Fc}$ electrodes respectively (Fig. 4). Low $\Delta E(\leq 0.06 \mathrm{~V})$ were measured that confirms the good reversibility of our system. We recorded CV signals at different scan rates $(v)$. A linear curve was obtained when plotting $I_{\max } v s . v$ for the three electrodes that allowed us to demonstrate the covalent attachment of the probeson surface (see Supplementary information). The electron transfer rate constants $\left(k_{\mathrm{et}}\right)$ were calculated as described by Yu et al.[24]. The obtained values were similar to those reported by our group with comparable stem-loop structures bond to the electrode through a different linker[9]. The $k_{\mathrm{et}}$ values calculated for $\mathrm{N}_{3} \mathrm{In}$ ' $1 \mathrm{Fc}$ and $\mathrm{Tb}\left(\mathrm{N}_{3}\right)_{3} \operatorname{In}$ ' $4 \mathrm{Fc}$ probes were slightly lower than the (DTPA) $)_{2} \mathrm{In} 4 \mathrm{Fc} k_{\mathrm{et}}$. This result can be relatedto the greater length of the linker used for the "click" reaction that impact theelectron transfer of ferrocenedue to its higher distance to the electrode.

\subsection{Surface coverage of the functionalized gold electrodes}

By integrating the oxidation and reduction peaks observed by $\mathrm{CV}$, the charge transferred to the electrode $(Q)$ can be calculated as described previously[25].Then, the total amount of bound ferrocene units onto the electrode $\Gamma$ can be quantitatively evaluated by using the equation $\Gamma=Q_{o x} / n F A$, where $n$ is the number of electrons transferred ( $n=1), F$ the Faraday constant (coulombs per equivalent), and $A$ is the effective surface area (square centimeters). That permits to estimate the amount of probes boundto the electrode dividing $\Gamma$ by the number of ferrocene per oligonucleotide (Table 3 ).

Table 3. Surface coverage of the functionalized gold electrodes.

\begin{tabular}{lll}
\hline Oligonucleotides & Surface coverage $\left(\mathrm{molcm}^{-2}\right)$ & Surface coverage $($ moleculescm \\
(-2)
\end{tabular}

In a general manner, the surface coverages indicated in the table 3 are similar to those obtained with ferrocene-modified oligonucleotides[5]. By comparing with other electroactivated grafting 
strategies reported in the literature, it is worth noting that the oligonucleotide grafting density obtained through our strategy of "click" reaction is higher than the one reported by Canete and Lai (from 6.88 $10^{11}$ to $1.8810^{12}$ molecules $\mathrm{cm}^{-2}$ ) on an azide-modified SAM made with C6 alkyl chains. In our case, the (DTPA) $)_{2}$ hexynyllinker probably offers a better accessibility for terminal alkynes to optimize the "click" reaction with azide oligonucleotides.

\subsection{Hybridization assays in complex medium}

Hairpin design were optimized in order to maintain hairpin folding stability in PBE buffer and complex medium together with an efficient opening towards complementary target binding. In and In' designs were compared. Assays achieved with the In sequence (resulting from (DTPA) ${ }_{2}$ In4Fc grafting) revealed a strong instability of the electrochemical signal, avoiding a clear variation upon binding. On Fig. 4, we can observe that the binding assay achieved at $100 \mathrm{pM}$ of DNA target led to an average variation of $16 \%$. The other experiments run at lower target concentrations failed to give significant results. One explanation of this lack of sensitivity could be that at low target concentration, the In hairpin preferred to stay folded on itself as the thermodynamic equilibrium favored selfassembling,instead of hybridizeto the complementary DNA target. On the other hand, In' hairpin gave significant and much reproducible variations of the electrochemical response upon binding with the complementary strand (see Fig. S5 in the Supplementary information). The electrodes functionalized with $\mathrm{N}_{3} \mathrm{In}$ ' $1 \mathrm{Fc}$ and $\mathrm{Tb}\left(\mathrm{N}_{3}\right)_{3} \mathrm{In}$ ' $4 \mathrm{Fc}$ probes were assessed for DNA detection.

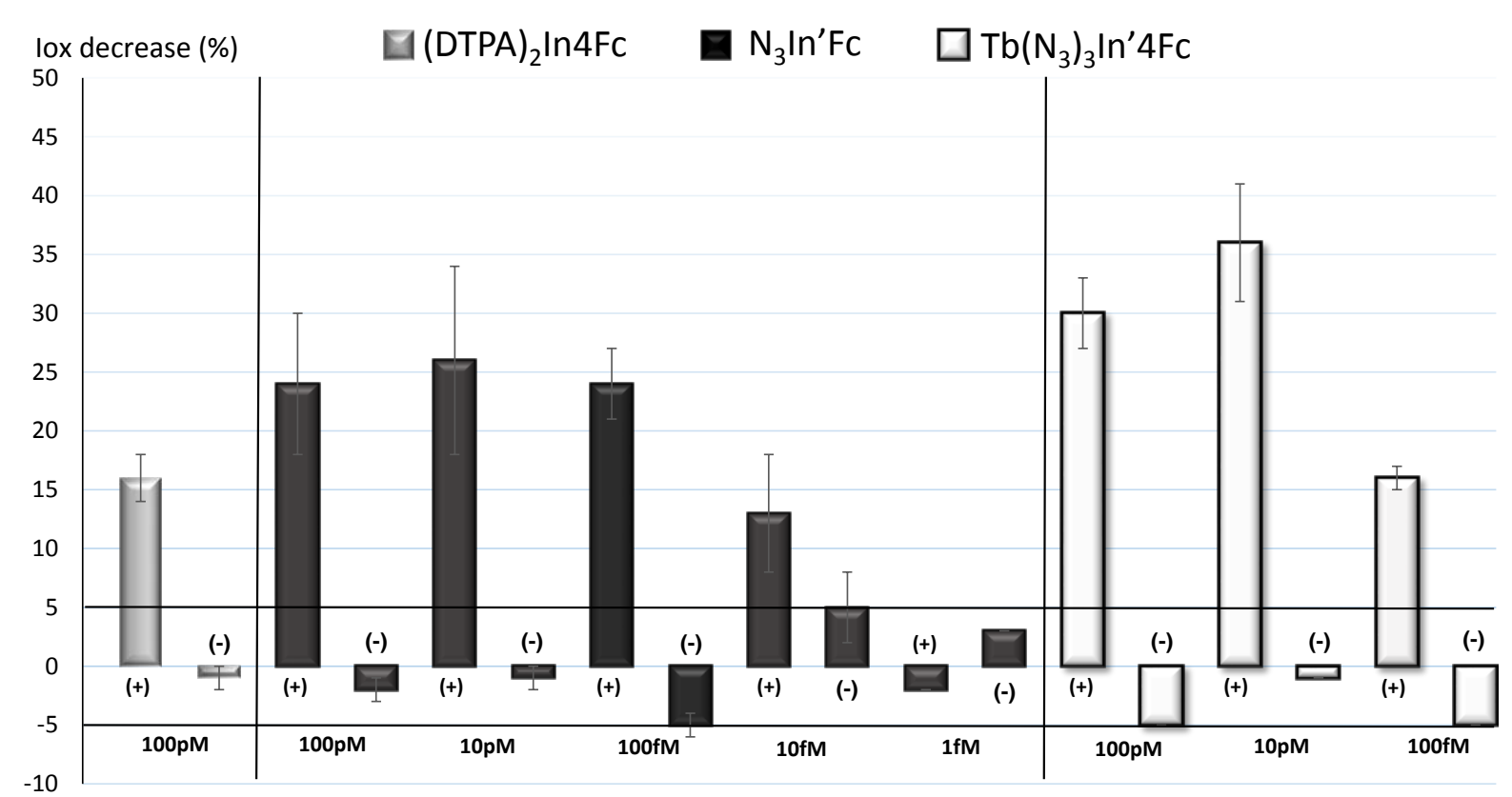

(+) : Complementary target; (-) : Non-complementary target

Fig.5.Hybridization assays with the complementary target (+) (sequence from Influenza virus genome) and the non-complementary target (-) on the functionalized electrodes.Peak current $\left(I_{\mathrm{ox}}\right)$ variation on CVs (in percentage) after 1 hour of incubation with the DNA target at different concentrations (either $100 \mathrm{pM}, 10 \mathrm{pM}, 100 \mathrm{fM}, 10 \mathrm{fM}$ or $1 \mathrm{fM})$. The bare errors are the average of two or three experiments. The background signal is determined to be $\leq \pm 5 \%$ of Iox variation.

A notable variation of current was observed upon binding with the complementary target. Signal turn-off was never total, even at a target concentration higher than $100 \mathrm{pM}$ (data not shown). To explain the residual signal observed upon hybridization, Anne et al. hypothesized a certain flexibility of the duplex formed by short-DNA fragments[26]. In our case, the 40-base DNA target is probably 
too short to ensure total inhibition of the duplex elastic bending towards the electrode. A significant residual signal is observed even after duplex formation. The maximum variation observed at the plateau was around 25\% (between 100pM and 100fM) and 30\% (between $100 \mathrm{pM}$ and $10 \mathrm{pM}$ ) for $\mathrm{N}_{3} \mathrm{In}$ '1 $\mathrm{Fc}$ and $\mathrm{Tb}\left(\mathrm{N}_{3}\right)_{3} \mathrm{In}$ ' $4 \mathrm{Fc}$ functionalized electrodes respectively. Negative controls achieved with the non-complementary DNA did not show any significant variation (less than 5\% variation) confirming the good selectivity of the sensor. The detection threshold $(5 \%)$ was determined as the average value of three negative assays. A signal variation superior to this value was considered as a positive response. The detection limit was determined at $100 \mathrm{fM}$ for the $\mathrm{Tb}\left(\mathrm{N}_{3}\right)_{3} \operatorname{In}$ ' $4 \mathrm{Fc}$ and $10 \mathrm{fM}$ for the $\mathrm{N}_{3}$ In'1Fc electrodes respectively. The longer length of the linker used for $\mathrm{Tb}\left(\mathrm{N}_{3}\right)_{3} \operatorname{In}{ }^{\prime} 4 \mathrm{Fc}$ grafting could explain the more important variation recorded upon binding. On the other hand, the flexibility of the link is probably increased. At very low target concentration $(\leq 10 \mathrm{fM})$, the duplex formed has more room on the surface that permits elastic bending towards the electrode. The best detection limit was determined for $\mathrm{N}_{3} \mathrm{In}$ '1Fc electrode.Both $\mathrm{N}_{3} \mathrm{In}$ '1 $1 \mathrm{Fc}$ andTb( $\left.\mathrm{N}_{3}\right)_{3} \mathrm{In}$ '4 Fc sensors exhibit very good sensitivity by comparison with previous studies from our group performed with hairpin probes with a C6-thiol linker[9]. The electroactivated "click" reaction is a performant grafting strategy to elaborate ultra-sensitive sensors.

\subsection{Electrode stability in buffer}

The stability of the functionalized electrodes was studied in PBE. The functionalized gold electrodes were immersed in PBE and maintained at room temperature. The maximumintensity at Epa was recorded by CV and monitored over a period of 24 days (see Supplementary information). The PBE solution was changed every couple of days, immediately before CV analysis. Phares et al. reported a similar stability study with a monothiol oligonucleotide compared to atrithiol anchoring groups[27]. When stored for 24 days in an aqueous buffer at room temperature, the monothiol sensor exhibited a $\sim 70 \%$ loss in signaling current. In our case, the recorded signal exhibited a very slight decrease (less than 10\%) for both electrodes over the period. The results confirmed the excellent stability of the electrode in buffer and the pertinence of using a tetradental anchoring in order to increase the stability of the sensor over time.

3.8.ElecCell integrated device functionalization by "click" reaction with a fluorescent oligonucleotide probe

The ElecCell integrated device was used for the immobilization of a fluorescent oligonucleotide using the electrocatalyzed "click" reaction previously described. The system was characterized using a fluorescence microscope with an excitation wavelength of $525 \pm 25 \mathrm{~nm}$. After grafting, the average fluorescence recorded at the emission wavelength of $605 \pm 70 \mathrm{~nm}$ on the gold working electrode was 8 fold superior to those of the reference and counter electrodes considered asfluorescence background signal (see Supplementary information). The whole integrated device was treated under the same protocol of activation and grafting (as described in the experimental part). This experiment proved the selectivity of the grafting approach. The electrocatalyzed "click" reaction is pertinent for the specific addressing of a gold electrode in an integrated sensor without significant cross-reaction on the other electrodes of the device.

\section{Conclusion}

Ferrocenyl and azido-modified stem-loop oligonucleotides were successfully synthesized by solid-phase synthesis. Their immobilization by the potential-assisted "click" reaction on an electrochemical system was studied. This method permitted selective functionalization of gold electrode on an electrochemical microcell (ElecCell) device that integrated the working, counter and reference electrodes. Specific detection of the complementary DNA target was demonstrated in complex medium at 10 fMlevel. Perspectives of this work will be to demonstrate the addressing efficiency on a multi-electrode system, opening the route of the multiplex detection. 


\section{Acknowledgments}

The authors are grateful to project Marie Curie PIRSES-GA-2012-318053.L-G. Zamfir was supported by the strategic grant POSDRU/159/1.5/S/137750, "Project Doctoral and Postdoctoral programs support for increased competitiveness in Exact Sciences research" cofinanced by the European Social Found within the Sectorial Operational Program Human Resources Development 2007-2013.MicaëlRipert and Gabriel De Crozals PhD theses were financed by the French Ministry of Research. The work was partly supported by CAMPUS-France through PHC Project BRANCUSI No29504QL. Finally, the technological realizations and associated research works were partly supported by the French RENATECH network.

\section{References}

[1] E. Pibiri, P. Holzmeister, B. Lalkens, G.P. Acuna, P. Tinnefeld, Single-molecule positioning in zeromode waveguides by DNA origami nanoadapters, Nano Letters, 14 (2014) 3499-3503.

[2] C. Fan, K.W. Plaxco, A.J. Heeger, Electrochemical interrogation of conformational changes as a reagentless method for the sequence-specific detection of DNA, Proc. Natl. Acad. Sci., 100 (2003) 9134.

[3] C. Immoos, E., S. Lee, J., M. Grinstaff, W., Conformationally gated electrochemical gene detection, ChemBioChem, 5 (2004) 1100-1103.

[4] A.E. Navarro, N. Spinelli, C. Moustrou, C. Chaix, B. Mandrand, H. Brisset, Automated synthesis of new ferrocenyl-modified oligonucleotides: study of their properties in solution, Nucleic Acids Res., 32 (2004) 5310-5319.

[5] H. Brisset, A.E. Navarro, N. Spinelli, C. Chaix, B. Mandrand, The first automated synthesis of ferrocene-labelled phosphorothioate DNA probe: A new potential tool for the fabrication of DNA microarrays, Biotechnol. J., 1 (2006) 95-98.

[6] G. Chatelain, C. Chaix, H. Brisset, C. Moustrou, F. Fages, B. Mandrand, Synthesis of electrochemical probes for nucleic acid detection, Sensors and Actuators B, 132 (2007) 439-442.

[7] G. Chatelain, H. Brisset, C. Chaix, A thermodynamic study of ferrocene modified hairpin oligonucleotides upon duplex formation: applications to the electrochemical detection of DNA, New J. Chem., 33 (2009) 1139-1147.

[8] G. Chatelain, A. Meyer, F. Morvan, J.-J. Vasseur, C. Chaix, Electrochemical detection of nucleic acids using pentaferrocenyl phosphoramidate alpha-oligonucleotides, New J. Chem., 35 (2011) 893901.

[9] G. Chatelain, M. Ripert, C. Farre, S. Ansanay-Alex, C. Chaix, A "four-ferrocene" modified stem-loop structure as a probe for sensitive detection and singlebase mismatch discrimination of DNA, Electrochimica Acta, 59 (2012) 57-63.

[10] N.K. Devaraj, P.H. Dinolfo, C.E.D. Chidsey, J.P. Collman, Selective functionalization of independently addressed microelectrodes by electrochemical activation and deactivation of a coupling catalyst, J. Am. Chem. Soc., 128 (2006) 1794-1795.

[11] N.K. Devaraj, J.P. Collman, Copper catalyzed azide-alkyne cycloadditions on solid surfaces: applications and future directions, QSAR \& Combinatorial Science, 26 (2007) 1253-1260.

[12] S.J.P. Canete, R.Y. Lai, Fabrication of an electrochemical DNA sensor array via potential-assisted "click" chemistry, Chem. Comm., 46 (2010) 3941-3943.

[13] A. Furst, S. Landefeld, M. Hill, G., J. Barton, K., Electrochemical patterning and detection of DNA arrays on a two-electrode platform, J. Am. Chem. Soc., 135 (2013) 19099-19102.

[14] M. Ripert, C. Farre, C. Chaix, Selective functionalization of Au electrodes by electrochemical activation of the "click" reaction catalyst, Electrochimica Acta, 91 (2013) 82-89.

[15] Z.-g. Yu, R.Y. Lai, A reagentless and reusable electrochemical DNA sensor based on target hybridization-induced stem-lopp probe formation, Chem. Comm., 48 (2012) 10523-10525. 
[16] C. Christophe, F. Sekli-Belaidi, J. Launay, P. Gros, E. Questel, P. Temple-Boyer, Elaboration of integrated microelectrodes for the detection of antioxidant species, Sens. Actuators, B, 177 (2013) 350-356.

[17] E. Vanhove, A. Tsopela, L. Bouscayrol, A. Desmoulin, J. Launay, P. Temple-Boyer, Final capping passivation layers for long-life microsensors in real fluids, sens. Actuators, B, 178 (2013) 350-358.

[18] F. Ricci, R.Y. Lai, A.J. Heeger, K.W. Plaxco, J.J. Sumner, Effect of Molecular Crowding on the Response of an Electrochemical DNA Sensor, Langmuir, 23 (2007) 6827-6834.

[19] J.A. Burns, J.C. Butler, J. Moran, G.M. Whitesides, Selective reduction of disulfides by tris(2carboxyethyl)phosphine, J. Org. Chem., 56 (1991) 2648-2650.

[20] C. Fan, K.W. Plaxco, A.J. Heeger, Biosensors based on binding-modulated donor-acceptor distances, Trends in Biotechnol., 23 (2005) 186-192.

[21] A.-E. Radi, J.L.A. Sanchez, E. Baldrich, C.K. O'Sullivan, Reagentless, Reusable, ultrasensitive electrochemical molecular beacon aptasensor, J. Am. Chem. Soc., 128 (2006) 117-124.

[22] D. Han, Y.-R. Kim, J.-W. Oh, T.H. Kim, R.K. Mahajan, J.S. Kim, H. Kim, A regenerative electrochemical sensor based on oligonucleotide for the selective determination of mercury(II) Analyst, 134 (2009) 1857-1862.

[23] T. Chan, R., R. Hilgraf, K.B. Sharpless, V. Fokin, V., Polytriazoles as copper(I)-stabilizing ligands in catalysis, Organic Letters, 6 (2004) 2853-2855.

[24] H.-Z. Yu, C.-Y. Luo, C.G. Sankar, D. Sen, Voltammetric procedure for examining DNA-modified surfaces: quantitation, cationic binding activity, and electron-transfer kinetics, Anal. Chem., 75 (2003) 3902-3907.

[25] C. Farre, N. Spinelli, A. Bouchet, C. Marquette, B. Mandrand, F. Garnier, C. Chaix, Synthesis and electropolymerisation studies of water-soluble pyrrole-ferrocene derivatives towards biochip device application, Synth. Met., 157 (2007) 125-133.

[26] A. Anne, C. Demaille, Dynamics of electron transport by elastic bending of short DNA duplexes. Experimental study and quantitative modeling of the cyclic voltammetric behavior of 3 '-ferrocenyl DNA end-grafted on Gold, J. Am. Chem. Soc., 128 (2006) 542-557.

[27] N. Phares, R.J. White, K.W. Plaxco, Improving the Stability and Sensing of Electrochemical Biosensors by Employing Trithiol-Anchoring Groups in a Six-Carbon Self-Assembled Monolayer, Anal. Chem., 81 (2009) 1095-1100. 